\section{Validating internal hierarchies: Reply to Deutsch}

\author{
MARI RIESS JONES \\ Ohio State University, Columbus, Ohio
}

"I can't remember things before they happen," says Lewis Carroll's Alice. And the White Queen replies, "It's a poor sort of memory that works only backwards." From Through the Looking Glass. $^{1}$

Alas, I share with Alice an ordinary memory, one that operates backward, not forward, in time. But, I am flattered that Deutsch (1982) attributes to me the clairvoyance required to respond to an article (i.e., Deutsch \& Feroe, 1981) that was published a year after the article (Deutsch, 1980) I considered in Jones (1981a). ${ }^{2}$ With sleight-of-hand worthy of the Mad Hatter, Deutsch (1982) attempts to shift the focus from her earlier research to a recently published essay with Feroe. It is tempting to yield to Deutsch's wiles here, because the system Deutsch and Feroe (1981) have outlined poses many problems for serious researchers in this field. However, in the interest of brevity I shall, for the most part, resist this temptation here.

Instead, let me restate that my main goal in Jones (1981a) was to highlight, for newcomers to serial pattern research, some theoretical issues and attendant methodological problems. Deutsch's (1980) research clearly illustrates a number of pitfalls of which researchers should be aware. Her recent comments (Deutsch, 1982) notwithstanding, the 1980 report remains as a good example of what "not to do" in experimental research with patterned sequences. Naturally, Deutsch disagrees. However, in her disagreement she has inaccurately portrayed my position. To set the record straight, I make eight points:

(1) Deutsch claims I attack a "nonexistent model" when I suggest that "Deutsch apparently means not a particular rule configuration, but a two-level 'hierarchy of subsequences" " (p. 499, Jones, 1981a). To the contrary, a two-leveled sequence hierarchy was precisely the model outlined in Deutsch (1980). Since she failed to define what she meant by hierarchy, her model must be taken at face value. Although Deutsch (1982) states that my inference here is "unequivocally false," I confess to bafflement about

Requests for reprints may be addressed to Mari Riess Jones, Department of Psychology, Ohio State University, 404-C W. 17th Avenue, Columbus, Ohio 43210 . The author is grateful to Susan Burbidge, Marilyn Boltz, Walter Johnson, and Gary Kidd for useful discussion. how a statement that opens with "Apparently" can be "unequivocally false."

(2) Deutsch unrealistically maintains that I should have known from her 1980 two-alphabet model, that in 1981 she would enlarge this to multiple alphabets. Nevertheless, my statements about alphabets are unequivocally true for the two-level model in Deutsch (1980). Furthermore, my analysis of how alphabets determine the set of rules to be used at any hierarchical level happens to be true for the system described later by Deutsch and Feroe (1981).

(3) Deutsch maintains that it is "unequivocally false" that she was attempting to reflect the special role of tonic and dominant notes in music when allowing the reference tone in her system to assume any serial location. Here I bow to her superior knowledge: only she can know why she introduced this feature. Her objection, however, reinforces my main point, which was not that she added this flexibility to her system, but that she gave no guidelines to the researcher for identification of the reference event. This inadequacy becomes an even more glaring problem in Deutsch and Feroe (1981), and finally it renders that system untestable (save, perhaps by Deutsch and Feroe, provided that they can agree on a reference event).

(4) Deutsch fails to comprehend my criticism that in her 1980 experiment she confounds rule configuration with the individual rules used. This is an elementary experimental failure, and her appeal to the Deutsch and Feroe article is irrelevant. The problem is clearly described in Jones (1981a).

(5) Deutsch entirely misconstrues my objections to her usage of the term "hierarchy." She claims I "insist" upon a narrow definition of the term. Not so. I merely illustrated the conventional meaning of "hierarchy." My complaint is not that her system fails to conform to convention, but that she is unclear about what she means by hierarchy. In a scientific enterprise, it is important to be clear about terms: "While there is nothing inherently wrong with introducing new meanings for old terms, it is important to be quite clear about it. Deutsch is not"' (p. 499, Jones, 1981a). Although the situation improves somewhat with Deutsch and Feroe (1981), the untutored reader, I fear, will still be confused. Even introduction of distinctive terms such as "sequence hierarchy" vs. "rule hierarchy" would have helped.

(6) Deutsch continues to ignore the need for using appropriate control sequences when drawing inferences about "internal representation" of higher levels of serial structure. She provides no rationale for her own, inappropriate, control sequences. And she maintains that ones I propose are irrelevant. She is wrong on this last point. On pages 501-502, I spe- 
cifically discuss typical control sequences necessary for verifying the "psychological reality" of Deutsch's "sequence hierarchy." These kinds of controls become more, not less, critical in establishing the validity of multilevel hierarchies such as those proposed by Deutsch and Feroe (1981). Accordingly, it is difficult to accept Deutsch's (1980) findings as convincing support for any hierarchical model, including the multilevel system outlined by Deutsch and Feroe (1981).

(7) Deutsch argues that other controls which I suggest, particularly ones involving time, have nothing to do with her model. In one sense, she is correct. But this is merely because her model has nothing to do with time. Neither time nor rhythm are part of the musical hierarchies in Deutsch (1980) or Deutsch and Feroe (1981). Paradoxically, these particular hierarchies can be strikingly confounded with accent levels within a temporal pattern, as I have shown (Jones, 1981a). (For an alternative theory that includes tempo and accent/rhythm hierarchies, see Jones, 1981b, in press). Nevertheless, in spite of a theoretical neglect of the time dimension, Deutsch (1980) does experimentally manipulate time and draws inferences about its effects upon encoding. Her recent comments (Deutsch, 1982) reveal that she fails to understand that such inferences are necessarily qualified by the nature of the experimental manipulations involved.

(8) On one point Deutsch is correct. I myopically failed to acknowledge parallel research on group theory applications in music (e.g., Babbitt, 1961; Lewin, 1977). Elsewhere, I have considered these important contributions (Hahn \& Jones, 1981; Jones, $1981 \mathrm{~b}$, in press).
Finally, I do not find any of Deutsch's criticisms of my tutorial essay compelling. She offers neither evidence nor rationale for her statements. I suggest that interested readers consult the original sources and decide for themselves who presents the more reasonable case.

\section{REFERENCES}

BAввitт, M. Set structure as a compositional determinant. Journal of Music Theory, 1961, 5, 72-94.

Deutsch, D. The processing of structured and unstructured tonal sequences. Perception \& Psychophysics, 1980, 28, 381-389.

Deutsch, D. The internal representation of information in the form of hierarchies. Perception \& Psychophysics, 1982, 31, 596-598.

Deutsch, D., \& Feroe, J. The internal representation of pitch sequences in tonal music. Psychological Review, 1981, 88, 503-522.

HAHN, J., \& Jones, M. R. Invariants in auditory frequency relations. Scandinavian Journal of Psychology, 1981, 22, 129-144.

Jones, M. R. A tutorial on some issues and methods in serial pattern research. Perception \& Psychophysics, 1981, 30, 492-504. (a)

Jones, M. R. Music as a stimulus for psychological motion: Part I. Some determinants of expectancies. Psychomusicology, 1981, 1, 34-51. (b)

Jones, M. R. Music as a stimulus for psychological motion: Part II. An expectancy model. Psychomusicology, in press.

LEwin, D. A label-free development for 12-pitch class systems. Journal of Music Theory, 1977, 21, 29-48.

\section{NOTES}

1. Lewis Carroll, Through the Looking-Glass (and what Alice found there). New York: Random House, 1965, p. 73.

2. The Deutsch and Feroe (1981) manuscript was referenced by Deutsch (1980) as "in preparation."

(Manuscript received March 4, 1982; accepted for publication March 12, 1982.) 